\title{
24-hour urinary free cortisol in children with paralytic syndromes and chronic pain
}

\author{
Natalia Orlova, Olena Riga \\ Department of Pediatrics No.1 and Neonatology, Kharkiv National Medical University, Ukraine
}

\section{ABSTRACT}

\begin{abstract}
Aim of the study: Measurement of 24-hour urinary free cortisol in children with paralytic syndromes with or without chronic pain. Hypothesis: urinary excretion of free cortisol in children with paralytic syndromes and chronic pain differs from urinary excretion of free cortisol in healthy children and children with paralytic syndromes without chronic pain.

Material and methods: 92 children were involved in the study. The age of the children ranged from 1 to 7 years. Study group included 64 children ( 40 boys, 24 girls) with paralytic syndromes, among them 38 children ( 24 boys, 14 girls) with chronic pain and 26 children ( 15 boys, 11 girls) without pain. Control group included 28 children (17 boys, 11 girls).

Results: Tetraparesis was observed more often among the children with paralytic syndromes. The ROC-analysis identified the relationship between low and high levels of cortisol in the 24-hour urinary free cortisol in children with paralytic syndromes and especially in those who have chronic pain only in the age group 0-2 years. In 13 children with paralytic syndromes and chronic pain, the trajectory of 24-hour urinary free cortisol was determined, 11 children among them have V level of GMFCS, 5 have pharmacological treatment and all children have more than two sources of pain.

Conclusions: We speculate that in some children with paralytic syndromes, the release of free cortisol in the urine may indicate increased cortisol production as a response to chronic stress (pain), and in some children, adrenal depletion. This opens the prospect of further research in this direction. Therefore, a non-invasive measurement of cortisol in daily urine will affect optimization of environment and monitoring of the child.
\end{abstract}

KEY WORDS:

children, chronic pain, paralytic's syndrome, 24-hour urinary free cortisol, trajectories of changes in urinary free cortisol.

\section{INTRODUCTION}

Acute and chronic pain has recently been considered as the most relevant health care problem. Pain in children is a particularly important health care issue all over the world. In 2008, the global paediatric community established the Initiative on Methods, Measurement, and Pain Assessment in Clinical Trials in order to develop common methods of assessment of pain in children [1]. A study conducted in Ukraine in 2010 showed that in most cases the goal of long-term chronic pain treatment was not achieved; the expected level of successful analgesia was not achieved in $80-90 \%$ of people [2].

To diagnose the pain, evaluation scales are usually used because of the behavioural signs of pain in children [3]. Pain assessment provides information about the location, duration, and characteristics of pain, as well as the impact of persistent pain on various aspects of a child's life, such as sleep, emotional state, relationships, development, and functional status [3].

\section{ADDRESS FOR CORRESPONDENCE:}

Natalia Orlova, Department of Pediatrics No.1 and Neonatology, Kharkiv National Medical University,

Ukraine, e-mail: norlova318@gmail.com 
With the aim of psychoendocrine substantiation of stress management in pain, the mechanisms of the relationship between chronic stress, cortisol dysfunction, and pain in adult patients were studied [4]. Patients generally complain of poor pain control and report that they receive little or no assistance with a variety of therapeutic options, such as non-opioid medications and physical therapy [5].

The long-term effect of chronic stress remains unchanged in chronic pain: the level of cortisol increases or decreases. Chronic stress-induced hyper- or hypocortisolism leads to various effects on tissues, and its results are confirmed and associated with pain [6].

\section{AIM OF THE STUDY}

Measurement of 24-hour urinary free cortisol in children with paralytic syndromes with or without chronic pain. Hypothesis: urinary excretion of free cortisol in children with paralytic syndromes and chronic pain differs from urinary excretion of free cortisol in healthy children and children with paralytic syndromes without chronic pain.

\section{MATERIAL AND METHODS}

\section{STUDY DESIGN AND SETTING}

A non-invasive, descriptive, single-centred, case-control study was conducted. We evaluated clinical and demographic data, determined the Gross Motor Function Classification System (GMFCS) level, and assessed pain, possible sources of pain, daily cortisol excretion (urinary free cortisol), and trajectories of changes in urinary cortisol [7].

\section{ETHICAL APPROVAL}

This study was approved by the Ethics Committee (protocol № 9 as of 16 October 2018), which was conducted with the involvement of underage patients and did not contain measures that could harm their health. The patients' parents were informed about the methods and scope of the study and gave their consent for their children to participate in this study.

\section{SAMPLING}

Ninety-two children were involved in the study. The age of the children ranged from 1 to 7 years. The study group included 64 children ( 40 boys, 24 girls) with paralytic syndromes, including 38 children ( 24 boys, 14 girls) with chronic pain and 26 children (15 boys, 11 girls) without pain. The control group included 28 children (17 boys, 11 girls) of the appropriate age range, who were recruited as volunteers from the out-patient depart- ment with routine paediatric observation without acute, chronic, genetic, or congenital diseases.

Inclusion criteria: children aged 1-7 years with paralytic syndromes according to ICD-10 (cerebral palsy G 80 , hemiplegia $G 81$, paraplegia and tetraplegia $G 82$, other paralytic syndromes G 83) associated with CNS damage caused by hypoxia, bleeding, thrombosis, trauma, or congenital brain defects.

Exclusion criteria: malignant neoplasms; HIV/AIDS; degenerative diseases of the nervous system; demyelinating disorders; chromosomal diseases; diseases with impaired renal function; orphan diseases; and those who did not agree to participate in the study.

\section{DATA COLLECTION}

The study included a detailed scrutiny of medical history and analysis of medical documents to determine the sources of pain (the child's diagnosis; paralytic syndromes; possible source and presence of pain; the degree of pain syndrome), a detailed assessment of the child's objective examination, and anthropometric measurements - height, weight, and movement disorders according to the GMFCS [7].

To determine a possible source of pain or a combination of pains a specially designed "Checklist" was used, which included 4 categories: somatic pain (5 points), visceral pain ( 9 points), neuropathic pain (5 points), and protein-energy malnutrition (2 points). During a child's physical assessment, the data about a possible source of pain marked as "Yes" entered a specifically developed card ("Checklist") - refer to Supplementary Materials (Supp. 1) [8].

In order to determine the degree of chronic pain in children with impaired communication skills, i.e. nonverbal children, we used the r-FLACC rating scale (Revised Face, Legs, Activity, Cry, and Consolability Scale). It is freely available on the Internet and does not require permission for its use [9]. The scale is based on determining the degree of pain by the sum of points: 0 points relaxed/comfortable; $1-3$ points - mild discomfort; $4-6$ points - moderate pain; $7-10$ points - severe pain. Pain evaluation with the r-FLACC scale was performed by parents accompanied by a physical therapist and a paediatrician.

Determination of free cortisol in the 24-hour urine collection from children was performed by enzyme immunoassay on a Labline-90 analyser (Austria) using a commercial test system manufactured by LDR (LABOR DIAGNOSTIKA NORD GmbH \& Co., KG, Germany) according to the provided instruction. A total of 118 portions of urine were collected during the examination of the observation groups: 92 portions of urine in children only once and 26 portions in 13 children with paralytic syndromes and chronic pain twice in order to deter- 
mine the trajectory of cortisol secretion in the urine (first point and last point), within an interval of 6 to 36 months.

The 24-hour urinary free cortisol in the children with paralytic syndromes with pain and without pain was compared with the 24-hour urinary free cortisol of the healthy children, and with reference values depending on the age of other children tested aged from 0 to 2 , and $>2-8$ years old $[10,11]$.

\section{ANALYSIS}

Statistical analysis was performed with the program MedCalc version 14.8 - (C) 1993 - 2014 MedCalc Software bvba (Acacialaan 22 B - 8400 Ostend, Belgium). Descriptive analysis and comparison of 2 proportions by Fisher test were performed. We used the Kruskal-Wallis test to compare more than 2 independent samples and Receiver Operating Characteristic (ROC) curve analysis to calculate the sensitivity and specificity, relative risk (RR), and their 95\% confidence interval (CI). The difference in parameters was considered statistically significant at $p<0.05$.

\section{RESULTS}

Table 1 presents clinical and demographic characteristics of the children with paralytic syndromes.

Tetraparesis was observed more often among the children with paralytic syndromes.

In the children with paralytic syndromes and chronic pain, the frequency of $\mathrm{V}$ level motor dysfunction was significantly increased, while in the children with paralytic syndromes without chronic pain it was at level II and III $(\mathrm{RR}=2.90$; 95\% CI: 1.63-5.21; $p=0.0004)$.

In the group of children with paralytic syndromes and chronic pain, moderate pain was observed more often: $1-3$ points $-12(31.6 \%), 4-6$ points $-20(52.6 \%)$, $>7$ points $-5(13.2 \%) ; p=0.0006$.

The analysis of the "Checklist" card results revealed a statistically significant increase in the frequency of children with paralytic syndromes and chronic pain who had more than 2 sources of pain $(p=0.0001)$. The types of pain observed in the children with paralytic syndromes and chronic pain were somatic, neuropathic, and visceral. The use of this card allowed us to determine the main pathophysiological types of pain in children with paralytic syndromes and chronic pain [8].

There was no significant difference between 24-hour urinary free cortisol in the children with paralytic syndromes and chronic pain, those without pain, and the control group aged 0-2 years and $>2-8$ years (Table 2 ).

We wondered if the 24-hour urine free cortisol values were outside the normal maximum and minimum values of healthy children in children with paralytic syndromes.

We used ROC-analysis with cut-off points $>76.67$ $\mu \mathrm{g} / 24$ hours (maximal value of control group) and $<0.98$ $\mu \mathrm{g} / 24$ hours (minimal value of control group) in children under 2 years of age.

We obtained an association with variations of 24-hour urinary free cortisol in children 0-2 years with paralytic syndromes and chronic pain: for $>76.67 \mu \mathrm{g} / 24$ hours, sensitivity $100 \%$ (95\% CI: $47.8-100)$ and specificity $100 \%$ (95\% CI: 54.1-100), $p<0.001$; for $<0.98 \mu \mathrm{g} / 24$ hours, sensitivity $100 \%$ (95\% CI: 47.8-100) and specificity $100 \%$

TABLE 1. Clinical and demographic data of the children with paralytic syndromes

\begin{tabular}{|l|c|c|c|}
\hline Data & $\begin{array}{c}\text { Children with paralytic } \\
\text { syndromes and chronic } \\
\text { pain, } \\
(n=38)\end{array}$ & $\begin{array}{c}\text { Children with paralytic } \\
\text { syndromes without chronic } \\
\text { pain, } \\
(n=26)\end{array}$ & $p$ \\
\hline $\begin{array}{l}\text { Age, years } \\
\text { Me [min; max] }\end{array}$ & $\begin{array}{c}5 \text { years 4 months } \\
3.35[0.3 ; 7]\end{array}$ & $\begin{array}{c}3 \text { years 3 months } \\
3.15[0.11 ; 6.3]\end{array}$ & 0.6872 \\
\hline Male & $24(63.2 \%)$ & $15(57.7 \%)$ & 0.6872 \\
\hline Female & $14(36.8 \%)$ & $11(42.3 \%)$ & 0.1908 \\
\hline Spastic paraparesis & $3(7.9 \%)$ & $5(19.2 \%)$ & 0.8135 \\
\hline Spastic tetraparesis & $18(47.3 \%)$ & $13(50.0 \%)$ & 0.9192 \\
\hline Dyskinetic tetraparesis & $7(18.4 \%)$ & $5(19.2 \%)$ & 0.1716 \\
\hline Double hemiplegia & $10(26.3 \%)$ & $3(11.5 \%)$ & 0.0003 \\
\hline GMFCS & & & 0.0126 \\
\hline II level & $2(5.2 \%)$ & $11(42.3 \%)$ & 0.4819 \\
\hline III level & $2(5.2 \%)$ & $7(26.9 \%)$ & 0.0005 \\
\hline IV level & $6(15.7 \%)$ & $6(23.0 \%)$ & $2(7.7 \%)$ \\
\hline V level & $28(73.6 \%)$ & & \\
\hline
\end{tabular}


TABLE 2. The results of statistical analysis of the study of 24-hour urinary free cortisol in the observation groups, Me [min; max]

\begin{tabular}{|c|c|c|c|c|}
\hline Indicator & \multicolumn{4}{|c|}{ Groups of children } \\
\hline \multicolumn{5}{|l|}{$0-2$ years } \\
\hline \multirow[t]{2}{*}{$\begin{array}{l}\text { Urinary cortisol, } \\
\mu \mathrm{g} / 24 \text { hours }\end{array}$} & $\begin{array}{c}\text { Children with paralytic } \\
\text { syndromes and chronic } \\
\text { pain. } \\
(n=17)\end{array}$ & $\begin{array}{l}\text { Children with paralytic } \\
\text { syndromes without pain. } \\
\qquad(n=5)\end{array}$ & $\begin{array}{l}\text { Healthy children } \\
\qquad(n=6)\end{array}$ & Kruskal-Wallis test \\
\hline & $\begin{array}{c}8.93 \\
{[1.81 ; 56.05]}\end{array}$ & $\begin{array}{c}6.78 \\
{[1.57 ; 64.68]}\end{array}$ & $\begin{array}{c}7.15 \\
{[3.15 ; 15.69]}\end{array}$ & $\begin{array}{c}\mathrm{H}=0.71 . \\
p=0.6999\end{array}$ \\
\hline \multicolumn{5}{|l|}{$>2-8$ years } \\
\hline \multirow[t]{2}{*}{$\begin{array}{l}\text { Urinary cortisol, } \\
\mu \mathrm{g} / 24 \text { hours }\end{array}$} & $\begin{array}{c}\text { Children with paralytic } \\
\text { syndromes and chronic } \\
\text { pain } \\
(n=22)\end{array}$ & $\begin{array}{l}\text { Children with paralytic } \\
\text { syndromes without pain. } \\
\quad(n=21)\end{array}$ & $\begin{array}{l}\text { Healthy children. } \\
\qquad(n=22)\end{array}$ & Kruskal-Wallis test \\
\hline & $\begin{array}{c}5.74 \\
{[1.63 ; 64.68]}\end{array}$ & $\begin{array}{c}4.21 \\
{[0.94 ; 117.29]}\end{array}$ & $\begin{array}{c}4.61 \\
{[1.44 ; 53.97]}\end{array}$ & $\begin{array}{c}\mathrm{H}=0.19 . \\
p=0.9083\end{array}$ \\
\hline
\end{tabular}

TABLE 3. Data on the trajectory of changes of the 24-hour urinary free cortisol in children with paralytic syndromes and chronic pain

\begin{tabular}{|c|c|c|c|c|c|}
\hline № & $\begin{array}{l}\text { GMFCS } \\
\text { (level) }\end{array}$ & $\begin{array}{l}\text { r-FLACC } \\
\text { (points) }\end{array}$ & Analgesic therapy & $\begin{array}{c}\text { Number of sources } \\
\text { of pain }\end{array}$ & $\begin{array}{l}\text { The trajectory } \\
\text { of the curve }\end{array}$ \\
\hline P1 & V & 8 & Yes & 5 & Flattened \\
\hline P2 & V & 9 & Yes & 6 & Flattened \\
\hline P3 & V & 8 & No & 5 & Flattened \\
\hline P4 & V & 5 & No & 2 & Increased \\
\hline P5 & V & 2 & No & 3 & Flattened \\
\hline P6 & V & 4 & Yes & 1 & Increased \\
\hline P 7 & V & 5 & Yes & 7 & Reduced \\
\hline $\mathrm{P} 8$ & II & 6 & No & 2 & Reduced \\
\hline P9 & III & 1 & No & 4 & Increased \\
\hline $\mathrm{P} 10$ & V & 5 & No & 5 & Flattened \\
\hline P 11 & V & 4 & No & 3 & Flattened \\
\hline P 12 & V & 5 & Yes & 5 & Increased \\
\hline P 13 & V & 5 & No & 6 & Flattened \\
\hline
\end{tabular}

(95\% CI: 54.1-100), $p<0.001$. No such relationship was found for the age group $>2-8$ years.

The ROC-analysis identified the relationship between low and high levels of cortisol in the 24-hour urinary free cortisol in children with paralytic syndromes and especially in those who have chronic pain only in the age group 0-2 years. This was confirmed by the results of studying the trajectories of excretion of 24-hour free urinary cortisol, which were determined in time.

In 13 (34.2\%) children with paralytic syndromes and chronic pain, the trajectory of 24-hour urinary free cortisol was determined; 11 (84.6\%) children among them had level V GMFCS, 5 (38.5\%) had pharmacological treatment, and all children have more than 2 sources of pain (Table 3).

Below we provide a series of clinical comparisons with urinary cortisol trajectories (Fig. 1).
Determination of the trajectories of 24-hour urinary free cortisol in the children with paralytic syndromes and chronic pain allowed us to establish the following trends in adrenal function over time. Thus, 7 (53.8\%, $p=0.7790$ ) children had a flattened trajectory at the low and below normal levels of cortisol. All children had level V GMFCS and more than 3 sources of pain. Two (15.4\%) children eventually developed rapid depletion of the adrenal glands associated with hypercortisolism. Among $4(30.7 \%)$ children showing an increase in the trajectory of daily urine cortisol over time, the next trend was identified: in 3 children with ultra-low daily cortisol the trajectory increased to normal values, and 1 child showed an increase in hypercortisolism over time. This can be explained by different functional states of the children, different sources of pain, and different rehabilitation interventions. Nevertheless, we believe that in children with 
paralytic syndromes against the background of central and peripheral nervous systems disorders and chronic pain, complex mechanisms of regulation of the hypothalamic-pituitary-adrenal system occur. Nine (69.2\%, $p=0.2274)$ children with paralytic syndromes and chronic pain, judging by the daily excretion of cortisol and the study of its trajectory, developed depletion of the adrenal glands at early and preschool age.

\section{DISCUSSION}

Over the past decades, medical science has paid more and more attention to the diagnosis and study of the pain mechanism in the paediatric population. According to experts in chronic pain in children, it occurs in $12 \%$ of all paediatric patients, which negatively affects the quality of life of children and their families [12]. Chronic pain is particularly frequently associated with disability [13].

Published research demonstrated changes in the level of cortisol in biological fluids (saliva, urine, blood) and hair in children $[5,6]$. Research covered different age categories, nosological forms, and conditions. The content of serum cortisol in newborns was studied [14]. Urinary free cortisol is often used by paediatric pulmonologists to interpret the suppressive effects of inhaled corticosteroids and adrenal function. It was proven that the daily free urinary cortisol is more valuable for the diagnosis of hypercortisolism than hypocortisolism [15].

However, there are some published studies that associated pain with changes in cortisol levels. They also covered different samples and different types of pain. There was a long-term increase in the basal level of salivary cortisol in children who were born prematurely and underwent procedural pain [16]. There is an interesting work by Ellen W. Yeung et al. concerning long-term measurement of cortisol and its impaired regulation in children with abuse, clinical pain (fibromyalgia), and distress [17].

The object of our study was daily urine cortisol in children of early and preschool age with paralytic syndromes, and in particular those who had pain. The development of paralytic syndromes associated with musculoskeletal pain as well as other sources of pain accompanying paralysis in children produces a long-term stress reaction in the child's body. Our hypothesis was that in children with paralytic syndromes and chronic pain, hyper- or hypocortisolism is observed, in contrast to healthy children and children with paralytic syndromes without chronic pain.

Regulation of stress reactivity using the hypothalamic-pituitary-adrenal system is a fundamental priority of all organisms, and stress responses are not only critical for survival, but can also cause physical harm [18].

Although the measurement of urinary excretion of corticosteroids has been used to assess adrenal function for over 50 years, it is mostly used to diagnose Cushing's syndrome or adrenal cancer. The advantage of the method of measuring daily excretion of corti-

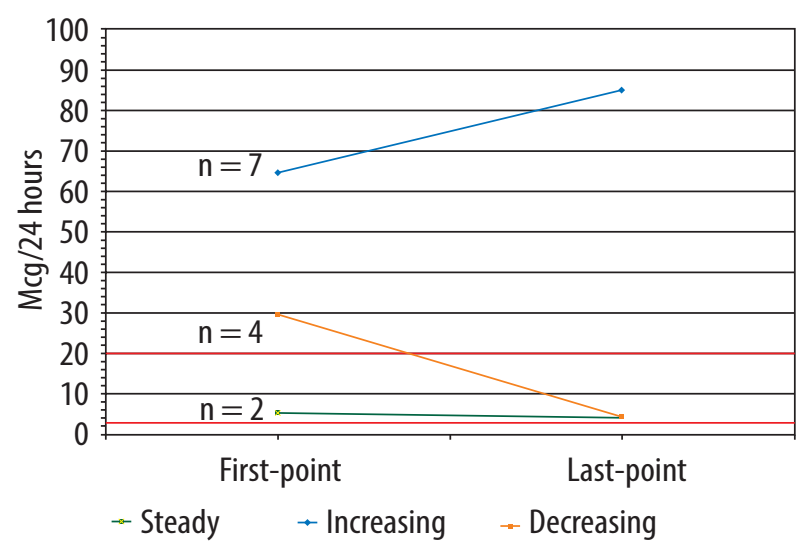

FIGURE 1. The trajectory of 24-hour free cortisol in the urine of children with paralytic syndromes and chronic pain

sol in urine over measuring cortisol in serum is that it gives an integrated index of steroid production during 24 hours, while measurements of serum cortisol provide information only for a certain point in time. Moreover, corticotropin and cortisol are secreted by discrete impulses, and due to that their concentration in the blood plasma periodically rises and falls. Urinary cortisol excretion is the result of normal glomerular filtration of serum free cortisol. Although the level of cortisol in urine constitutes less than $1 \%$ of cortisol excreted per day, it provides a reliable indicator of its secretion. Accordingly, Jung C et al. confirmed that cortisol in saliva and urine accurately reflects the concentration of free cortisol in blood plasma [19-23].

The next important point for discussion is the variation in cortisol production at different ages. Stress response of the hypothalamic-pituitary-adrenal axis varies greatly with age, which is associated with the maturation of the adrenal glands and their sensitivity to corticotropin [24]. It is believed that in the peripubertal period, reactions to stress are more pronounced than in adults, and they depend on parental work and social stimulation [25]. For that matter, we selected a population of children with paralytic syndromes that differed from the population of healthy children both by different levels of parental care and by a decrease in socialization [26-28].

Our research has shown that daily level of free cortisol in urine in children with paralytic syndromes does not differ from the one in healthy children. However, differences were detected between the age categories. Until now, published data has suggested that free cortisol in children aged from 0 to 2 years old in daily urine was established [10, 11]. We analysed and compared the level of cortisol in daily urine in children of this age group and discovered the dependence of its increase and decrease in children with paralytic syndromes and pain syndrome, in contrast to their peers. Thus, we rejected the hypothesis for the children aged from 2 to 8 years and confirmed it for the children aged from 0 to 2 years.

Moreover, the originality of our study is in the research of the trajectories of changes in cortisol levels over 
time. We discovered similar findings in the study of mental health in children with autism [29]. Of course, those changes were influenced by various factors such as progression of paralytic syndrome, maturation of the adrenal glands, protein-energy malnutrition, medication, central nervous system disorders, relationships in the family, etc.

We suppose that the adrenal function in children with paralytic syndromes differs from the adrenal function in healthy children, especially in non-verbal children in the age group 0-2 years under medical supervision. Therefore, a non-invasive measurement of cortisol in daily urine will affect optimization of environment and monitoring of the child.

There were some inherent limitations associated with this study: firstly, the sample size. Our model was based on single-centre case-control study and was limited by the time and the number of children. We used only the first part of study: investigation of the diurnal cortisol and collection data for trajectory are ongoing. Secondly, there were very few prior studies, and there are some gaps in the studies relevant to diurnal cortisol, which influenced the methodology of our study. Our study was limited by the time interval. As a result, ROC-analysis detected a relationship between pain and urine cortisol only in children under the age of 2 years, which would bias the results of our overall and subgroup analysis toward the null hypothesis. Thirdly, we did not establish the relationship between other factors and adrenal function.

\section{CONCLUSIONS}

First, the 24-hour urinary secretion of free cortisol varies in children with paralytic syndromes and chronic pain. Secondly, the determination of daily free cortisol in urine is not one of the methods for diagnosing chronic pain in children with paralytic syndromes, but its variations may have diagnostic value as an additional criterion for assessing pain in the age group from 0 to 2 years. We speculate that in some children with paralytic syndromes, the release of free cortisol into the urine may indicate increased cortisol production as a response to chronic stress (pain), and in some children, adrenal depletion. This opens the prospect of further research in this direction.

\section{DISCLOSURE}

The authors declare no conflict of interest.

\section{REFERENCES}

1. Liossi C, Howard RF. Pediatric Chronic Pain: Biopsychosocial Assessment and Formulation. Pediatrics 2016; 138: e20160331.

2. Shapoval-Deynega K, Rokhanskiy A, Riga O, et al. Ensuring Access to Pain Relief in Human Rights. Inter Collegas 2018; 5: 10-18.

3. WHO model formulary for children. Geneva, World Health Organization,. WHO Technical Report Series 2010; 958: 510.
4. Kara E Hannibal, Mark D Bishop. Chronic Stress, Cortisol Dysfunction, and Pain: A Psychoneuroendocrine Rationale for Stress Management in Pain Rehabilitation. Physical Therapy 2014; 94: 1816-1825.

5. Forest Tennant. Cortisol Screening in Chronic Pain Patients. Practical Pain Management. 12 (1). Available from: https://www.practicalpainmanagement.com/pain/cortisol-screening-chronic-pain-patients?page $=0,2$

6. Durán-Carabali LE, Henao-Pacheco ML, González-Clavijo AM, Dueñas Z. Salivary alpha amylase and cortisol levels as stress biomarkers in children with cerebral palsy and their association with a physical therapy program. Res Dev Disabil 2021; 108 : 103807.

7. Gross Motor Function Classification System for Cerebral Palsy. Available from: https://depts.washington.edu/dbpeds/Screening\%20Tools/GMFCS-ER.pdf

8. Orlova NV, Riga OO. Oryhinalnyi opytuvach dlia batkiv/zakonnykh predstavnykiv (opikuniv), «Cheklyst». Svidotstvo pro reiestratsiiu avtorskoho prava na tvir №88107 2019.

9. Malviya S, Vopel-Lewis, Burke T, et al. The revised FLACC Observational Pain Tool: Improved Reliability and Validity for Pain Assessment in Children with Cognitive Impairment. Pediatric Anesthesia 2006; 16: 258-265.

10. Boscaro M, Barzon L, Fallo F, et al. Cushing's syndrome. Lancet 2001; 357: 783-791.

11. Taylor RL, Machacek D, Singh RJ. Validation of a high-throughput liquid chromatography-tandem mass spectrometry method for urinary cortisol and cortisone. Clin Chem 2002; 48: 1511-1519.

12. Friedrichsdorf SJ, Postier AC, Eull D, et al. Pain outcomes in a US children's hospital: a prospective cross-sectional survey. Hospital Pediatrics 2015; 5: 18-26.

13. Zale EL, Krista L. Lange, Sherecce A. Fields et al. The relation between pain-related fear and disability: a Meta-analysis. J Pain 2013; 14: 1019-1030.

14. Pak C Ng. Is There a "Normal" Range of Serum Cortisol Concentration for Preterm Infants? Pediatrics 2008; 122: 873.

15. Pescollderungg L, Peroni DG, Pietrobelli A, Radetti G. Inhaled corticosteroids and urinary free cortisol. Pediatrics 2003; 112 (6 Pt 1): 1464-1465.

16. Grunau RE, Weinberg J, Whitfield MF. Neonatal procedural pain and preterm infant cortisol response to novelty at 8 months. Pediatrics 2004; 114: e77-e84

17. Yeung EW, Davis MC, Ciaramitaro MC. Cortisol Profile Mediates the Relation Between Childhood Neglect and Pain and Emotional Symptoms among Patients with Fibromyalgia. Ann Behav Med 2016; 50: 87-97.

18. Herman JP, Nawreen N, Smail MA, et al. Brain mechanisms of HPA axis regulation: neurocircuitry and feedback in context Richard Kvetnansky lecture. Stress 2020; 23: 617-632.

19. van Aken MO, Pereira AM, van Thiel SW, et al. Irregular and frequent cortisol secretory episodes with preserved diurnal rhythmicity in primary adrenal Cushing's syndrome. J Clin Endocrinol Metab 2005; 90: 1570 .

20. Chan KC, Lit LC, Law EL, et al. Diminished urinary free cortisol excretion in patients with moderate and severe renal impairment. Clin Chem 2004; 50: 757.

21. Nieman LK, Biller BM, Findling JW, et al. The diagnosis of Cushing's syndrome: an Endocrine Society Clinical Practice Guideline. J Clin Endocrinol Metab 2008; 93: 1526.

22. Raff H, Auchus RJ, Findling JW, et al. Urine free cortisol in the diagnosis of Cushing's syndrome: is it worth doing and, if so, how? J Clin Endocrinol Metab 2015; 100: 395.

23. Jung C, Greco S, Nguyen HH, et al. Plasma, salivary and urinary cortisol levels following physiological and stress doses of hydrocortisone in normal volunteers. BMC Endocr Disord 2014; 14: 91. 
24. Schroeder RJ, Henning SJ. Roles of plasma clearance and corticosteroid-binding globulin in the developmental increase in circulating corticosterone in infant rats. Endocrinology 1989; 124: 2612-2618.

25. Romeo RD. Pubertal maturation and programming of hypothalamic-pituitary-adrenal reactivity. Front Neuroendocrinol 2010; 31: $232-40$

26. Eker L, Tüzün EH. An evaluation of quality of life of mothers of children with cerebral palsy. Disabil Rehabil 2004; 26: 1354-1359.

27. Raina P, O'Donnell M, Rosenbaum P, et al. The health and well-being of caregivers of children with cerebral palsy. Pediatrics 2005; 115: e626-e636.

28. Eker L, Tüzün EH. An evaluation of quality of life of mothers of children with cerebral palsy. Disabil Rehabil 2004; 26: 1354-1359.

29. Dykens EM, Lambert W. Trajectories of diurnal cortisol in mothers of children with autism and other developmental disabilities: relations to health and mental health. J Autism Dev Disord 2013; 43: 2426-2434. 